\title{
Negotiation and Romantic Relationships: How Strategic Negotiation Strategies Contribute to a Harmonious Relationships Between Couples?
}

\author{
Boyu Chen ${ }^{1, *, a, \dagger}$, Wenxin Dong ${ }^{2, *, b, \dagger}$
}

\author{
${ }^{1}$ Florida International University Miami, America \\ ${ }^{2}$ Beijing University of Agriculture, Beijing, China \\ *Corresponding author. Email: ${ }^{a}$ bchen017@fiu.edu ${ }^{b} 1829649557 @ q q . c o m$
}

These authors contributed equally.

\begin{abstract}
Negotiation is the continuous coordination of the two sides' joint efforts to expand the interests of both parties. In terms of the relationships between couples or partners, negotiation can be viewed as a special form of communication that aims to achieve a win-win situation in which both sides can feel satisfied, and thereby the quality of the relationship can be greatly improved. This study, through a review of the pertinent strategic negotiation theories, proposes that the romantic relationship between couples can be constructed by adopting active listening techniques and interest-based bargaining principles. As a result, this review article would theoretically discuss how strategic negotiation strategies can shed lights on couples' communication and practically put forward an array of suggestions for couples to construct a long-term healthy intimate relationship.
\end{abstract}

Keywords: strategic negotiation; romantic relationship; active listening; interest-based bargaining.

\section{INTRODUCTION}

Communication is the exchange of information between people, either through words, actions or through other behaviours [1]. In a romantic relationship, namely the relationships between couples or partners, communication can be said as one of the most crucial ways to enhance the quality of relationship for the two sides. Nonetheless, whilst it is well acknowledged that communication is of great significance for constructing a harmonious and sustainable intimate relationship. In reality, people have witnessed many counter-examples regarding how couples can fall into an intensive quarrel due to the inappropriate or unsmooth communication process.

To cope with these issues, it can be argued that business negotiation strategies may crucially shed light on those daily communications between couples. Negotiation, by definition, is a special format of communication aiming to resolve conflicts and achieve agreements, especially in those formal business and political occasions. In nowadays competitive business world, negotiation skills and relevant tactics are widely adopted for various objectives, including but not limited to negotiate a promotion campaign and payment, to sign a contract, to construct a partnership, so on and so forth.

Even though the aforementioned scenarios occur more frequently in business settings, they do have huge implications with regard to the life issues between couples. During communication between couples, there are a lot of bargaining events, with respect to the family spending, house purchasing, school selection for the kids, etc. Such communications, sometimes, can become extremely difficult if there existed diverged ideas between the couple, and the other party will easily become angry because his or her preferences are not met, and their opinions are not respected [1]. Thus, it can be reasonably argued that, those business negotiation strategies may also contribute to the enhancement of a romantic relationship by helping to solve the conflicts and reach a consensus.

This article, therefore, would especially focus on two most commonly applied negotiation strategies: active listening and interest-based bargaining skills to delineate how they would benefit non-business communications between lovers. Concerning the article structure, 
previous studies with regard to active listening and interest-based negotiation strategies are respectively reviewed and then discussed in romantic relationships. Finally, a conclusion is made in the end to talk about how future studies can combine strategic negotiation theories so as to make further contributions for communications in daily life.

\section{THE TACTIC OF ACTIVE LISTENING}

The first strategic negotiation tactic introduced in this study is "active listening". Theoretically, listening can be simply defined as a basic capability to obtain information through humans' hearing system [2]. Nevertheless, listening can be either passive or active, depending on the listeners' own purposes and intentions to obtain relevant information. In business negotiation settings, active listening has been proved as a very effective and functioning method to enhance mutual understanding, as it requires the listeners to pay extra attention, to invest in his or her emotions, and to try to understand the other's feelings by absorbing the counterparts' perceptions [3]. Thereafter, the probability of reaching a consensus would be greatly enhanced.

More specifically, there are some guidelines and principles to perform active listening. First of all, when actively listening to others, the listeners should never interrupt people and judge the contents or tones of what they are expressing [4]. Previous psychological research has shown that both interruptions and subjective judgments would lead to extensive dissatisfaction among the parties involved in the communication [4]. Thus, the foremost premise to conduct active listening in the negotiation is "listening without judging."

On the other hand, despite that during the communication responses are necessary, active listening, however, is not about instantly expressing the opinions when the other person stops talking. True active listening is not only in the manner of attention, but also in the behaviour of appropriately respond to the other party, with appropriate silence to show that they are digesting the other party's conversation [4]. Meanwhile, the silence time is also significant for both parties to think about the information behind the words.

Nevertheless, active listening does not mean to always keep silent until the end. Some interruptions and replies may also be performed during the conversation. For instance, previous studies have discussed that how the restatement of others' words can be beneficial to a clearer understanding of the meaning, as restating what partner said can clarify what the other person was trying to say [3]. Meanwhile, some follow-up questions can also lead to higher efficiency of mutual understand. Therefore, this implicates that active listening is not only regarding listening but a wise combination of listening and speaking.
The success factors include communication and interpersonal relationship, and professional knowledge and technology. The former accounts for $85 \%$ of the total, while the latter only accounts for $15 \%$. The greatest achievement of mankind comes from communication, and the greatest achievement comes from unwillingness to communicate. So, what is effective communication like? They have the same ideas, resonate with each other, reduce mutual suspicion, reduce friction, politics and differences of opinion. Effective communication is a common state of mind or emotion. Effective communication is to improve and promote our work level and quality of life. According to the research of Harvard University, effective communication includes three parts: conversation content, attitude and relationship. Therefore, effective communication must be skilfully prepared, create an atmosphere and be good at listening.

\section{ACTIVE LISTENING IN ROMANTIC RELATIONSHIPS}

In accordance with the review in the above section, it can be concluded that active listening can not only be applied in business negotiation, it also has lots of implications for communication in our daily life including the communications between couples. While this tactic might be considered as common sense; however, during actual communications, actively listening to others may not always be the case. In this situation, extant studies have discussed some reasons causing this issue, and this may further propose insights for couples' communication.

The first dimension of the causes is regarding the social-cultural impacts, especially in the eastern Asian cultural contexts where there is a relative high-power distance between the male and female [5]. As discussed in previous studies, the impact of family habit can be huge. If the parents don't show their offspring a good example and often demonstrate quarrelling in front of the children, then these people will not acquire an appropriate pattern of listening and will doom to continue to follow their parents' behavioural patterns when they start a family in the following life.

The second dimension of the reasons is about the characters and personalities [5]. According to the human character typologies, there exists a certain group of people who are individually paranoid and self-centred. When communicating with these types of people, it is highly possible to experience a hard time to ask them to keep actively listening, as they tend to stubbornly believe that their own opinions are all correct and everyone else is wrong. In the marriage, if one of the partners belongs to this type of person or if one is too dominant and tries to impose his or her will on the others, then the active listening may not effectively 
happen in the communication. Finally, the problem may occur due to the other existing problems between the spouse. If there are some pre-existed issues, or if the two sides already have massive resentment and conflicts, it is difficult to sit down and communicate with each other, or to have the patience to listen to each other.

The process of communication is a process of mutual communication, and communication is two-way. When we transmit our ideas to others, we should also listen to others. So is listening important for communication? Is learning to listen helpful to communication? Listening can help us get more information. Everyone's level of information expression is different. Some people are used to getting to the point, while others can't get to the point for a long time. For example, customers often ask us all kinds of questions and complaints, but most of the time, customers just want to find someone to vent their negative emotions and don't want to do anything about it. Or because in life in a bad mood, see what is not pleasing to the eye, catch what to take what to vent. These situations need us to listen attentively.

All in all, it is important to figure out what causes the inactive listening behaviours between the couple, and then the efforts should be paid into resolving these problems [5]. During the practice of actual listening, it is possible that the sensitive wordings may trigger feelings of guilt, shame, anxiety and defensiveness. It is reasonable that the instinct may be to go from being obedient to being rebuttal, wanting to prove the other person wrong right away. The conversation turns to confrontation. This time listen to each other calmly and rationally, first communicate what the other party wants to talk about, and then discuss the tone and attitude of the other party after both parties calm down.

\section{INTEREST-BASED NEOGOTIATION}

Active listening is undoubtedly a beneficial communicational strategy that is easy to be understood; however, sometimes the conflict may be due to more complicated reasons. On this occasion, only a more comprehensive analysis of the reasons for the conflict can mitigate the conflict. Amid these problems, interestbased bargaining methods can be very implicative for this sort of analysis.

By definition, interest-based negotiation or bargaining is a problem-solving and conflict mitigation approach that focalizes on the common needs and wants rather than the positions of the parties [6]. More specifically, a position is defined as the "want" itself, while the interest is why there is a "want" [6]. To illustrate what is the interest-based negotiation, the hard approach (aka. position-based approach) can be delineated first.
In detail, the objective of positional bargaining focuses on the positions or the principles rather than the interest embedded during the negotiation [7]. For instance, in the inter-governmental negotiation, the position could be the sovereignty of the country, the belief of religion or the political system of a country. In these scenarios, the positional bargaining may possibly reach a lose-win situation or lead to a zero-sum game in which one partner in the case would have to comprise, whether relentless or willing [7].

In contrast to positional bargaining, interest-based bargaining sets out to reach a win-win situation. The reasons that why interest-based bargaining could perform better in achieving beneficiary results for both sides is that it provides more alternative solutions to a problem [8]. Concerning a conflict or dispute, in many cases, people make decisions due to the latent benefits or interests they want to obtain. However, they may not always be conscious of those interests by themselves, and the lost the focal point of discussion and finally lead to a "dead end".

In sum, it can be summarized that the conflict, from the perspective of the interest-based negotiation paradigm, always means that there is a perceived divergence of interest, or a belief that parties' current aspirations cannot be achieved simultaneously. To solve these divergences, common interests have to be firstly detected and then mutually beneficial agreements could be made. In the next section, these methods are discussed with the common issues in romantic relationships in detail.

\section{INTEREST-BASED NEGOTIATION IN ROMANTIC RELATIONSHIP}

As has been reviewed, interest-based negotiation can be said an integrative process comprising an array of efforts in finding the agreed interests or common ground underlying the position so as to gain the opportunity to achieve a win-win situation. The proposition of this approach is applicable to the romantic relationship. Nonetheless, performing such tactic may not be an easy task in the romantic relationships

As to how to apply this approach to solving conflicts, previous studies have also discussed multiple rules to follow. To begin with, when a conflict seems to occur, it is highly necessary to "delay" it and not to really act a lot for the dispute [8]. It is because that at this moment, people can get very emotional and merely focus on their positions instead of the reasons for conflict. This tactic will provide precious time for an all-around consideration and preparation to solve the conflict.

After calming down, it is pivotal to take a new look at the problem, and to examine why the conflict would occur, what interests are behind the conflict and what 
are the solutions and evaluation criteria can be used in the negotiation process to meet the needs of both sides [9], which will essentially help open to a new window that leads to a reconsideration of the conflict.

At this stage, achieving the best solution to an interest-based negotiation requires an honest discussion of conditions that can make some alternatives. The discussion should be made in line with aligned interests reacting as the driving forces for the conflict [9]. If don't spend time asking for the 'whys' beneath the positions, the embedded reasons will be missing.

A compromise and trade-off are necessary to be implemented in order to achieve the utmost of interests. Negotiation compromise refers to the understanding and concession action made by one or both parties in order to reach an agreement. Compromise is a negotiation strategy, its purpose is to avoid deadlock in the negotiation process, so as to promote the success of the negotiation. There are two forms of negotiation compromise: understanding and concession. These two forms sometimes exist at the same time or separately in the time and content of negotiation, depending on the urgency and prerequisite of the issue. When a problem cannot be solved and is directly related to the subsequent negotiation, the understanding expressed by one party will lead to substantial concession - acceptance of the other party's position and demands; When it is not so urgent, compromise can be interpreted as giving up one's own attack and considering the other's position and demands. The existence of compromise forms at two levels of understanding and concession provides negotiators with the opportunity to examine the other party and review the negotiation situation, and also adds colour to the negotiation.

The results would have to at least impose a positive impact on the interactions between husband and wife [10]. If no such results can be made at once, it is possible to have a second analysis and discussion until the two sides can obtain positive feelings. Otherwise, the worst scenarios would be avoidance that has to be considered at last if no consensus can be reached. In the field of romantic relationships, it usually means divorce or break-up.

\section{REFLECTION AND CONCLUSION}

In conclusion, the intimate relationship is not a war that must determine who wins or who losses. The ideal consequence of a "romantic communication" is that both sides can feel satisfied with the decision. Consequently, as discussed in this article, active listening and interestbased negotiation can be effectively used to solve the conflicts existing between couples, indicating the importance of strategic negotiation principles in enhancing the romantic relationship quality. Meanwhile, a number of specific strategies have also been posed to apply in the communication process between couples. It is believed that as long as these simple principles can be employed, they would have significant positive impacts on the romantic relationship.

To restate aforementioned negotiation principles, first, taking the initiative to listen is always the cornerstone of communication in a romantic relationship. It is a very simple but efficacious way to strengthen the interpersonal relationships and mutual trust.

After that, if the problem and conflict are still lingering and cannot be solved due to high existence of complexities, then an analysis of the interests is recommended to be performed, and the solutions should be focalized on the interests rather than the positions. Even though these rules are seemingly easy, in reality, practices are indispensable to be made so as to realize the power of strategic negotiation management theories. Whilst some people are born as good negotiators, the majority of people have to specially acquire them as life-long lessons

Finally, other than the proposed two strategies in this study, future research could further investigate how to apply other negotiation skills to construct healthy romantic relationships, such as what and how other business negotiation strategies can positively impact the relationship between lovers. Only in this way, those unnecessary harms and disputes, such as domestic violence, can be avoided in the society.

\section{REFERENCES}

[1] Jang, D., Elfenbein, H. A., \& Bottom, W. P. (2018). More than a phase: Form and features of a general theory of negotiation. Academy of Management Annals, 12(1), 318-356.

[2] Royce, T. (2005). The negotiator and the bomber: Analyzing the critical role of active listening in crisis negotiations. Negotiation Journal, 21(1), 527.

[3] Noesner, G. W., \& Webster, M. (1997). Crisis intervention: Using active listening skills in negotiations. FBI L. Enforcement Bull., 66, 13.

[4] Weger Jr, H., Castle Bell, G., Minei, E. M., \& Robinson, M. C. (2014). The relative effectiveness of active listening in initial interactions. International Journal of Listening, 28(1), 13-31.

[5] Carroll, J. S., Badger, S., \& Yang, C. (2006). The ability to negotiate or the ability to love? Evaluating the developmental domains of marital competence. Journal of Family Issues, 27(7), 1001-1032. 
[6] Rahwan, I., Sonenberg, L., \& Dignum, F. (2003, July). Towards interest-based negotiation. In Proceedings of the second international joint conference on Autonomous agents and multiagent systems (pp. 773-780).

[7] Pasquier, P., Hollands, R., Rahwan, I., Dignum, F., \& Sonenberg, L. (2011). An empirical study of interest-based negotiation. Autonomous Agents and Multi-Agent Systems, 22(2), 249-288.

[8] Rahwan, I., Pasquier, P., Sonenberg, L., \& Dignum, F. (2009). A formal analysis of interest-based negotiation. Annals of Mathematics and Artificial Intelligence, 55(3), 253-276.

[9] Rahwan, I., Sonenberg, L., \& Dignum, F. P. (2003, July). On interest-based negotiation. In Workshop on Agent Communication Languages (pp. 383401). Springer, Berlin, Heidelberg.

[10] Koerner, A. F., \& Fitzpatrick, M. A. (2002). Toward a theory of family communication. Communication theory, 12(1), 7091. 